\title{
Athermal and Isothermal Martensitic Transformations Induced at Room Temperature by Ultra High Magnetic Field
}

\author{
S. Kajiwara, T. Kikuchi, H. Pal, T. Asano, M. Kosuge, M. Yuyama, K. Inoue and H. Wada \\ National Research Institute for Metals, 1-2-1 Sengen, Tsukuba 305, Japan
}

\begin{abstract}
Effects of ultra high magnetic field of both pulse and steady types on martensitic transformation have been studied, using $\mathrm{Fe}-\mathrm{Ni}-\mathrm{Mn}$, Fe-Ni-Mn-C alloys with the supplemental tests on Fe-Ni-C and Fe-NiCo-Ti alloys. It is found that the martensitic transformation is induced at room temperature not only athermally but also isothermally either by pulse magnetic field or by steady magnetic field for Fe-Ni-Mn and Fe-Ni-Mn-C alloys. This fact is in sharp contrast with that no martensite is induced by ultra high magnetic field for $\mathrm{Fe}-\mathrm{Ni}-\mathrm{C}$ and $\mathrm{Fe}-\mathrm{Ni}-\mathrm{Co}-\mathrm{Ti}$ alloys.
\end{abstract}

\section{INTRODUCTION}

Magnetic field is one of the important external physical quantities which affect properties of materials and has been the subject of interest and research for more than a century not only in pure physics but also in materials science. Especially, recent development of the instruments producing extremely high magnetic fields seems to give us completely new means to explore various properties in materials. In our research institute, we have recently succeeded in developing new experimental facilities which are able to produce one of the world-records in both pulse and static magnetic fields [1-3]. Among various research projects using these facilities, an investigation of effects of ultra high magnetic fields on martensitic transformation has been just initiated and, in this paper, we describe some of the interesting results in this new approach to study of martensitic transformation.

In the past decade, Kakeshita and his coworkers have extensively studied effects of magnetic field on martensitic transformation in various Fe-based alloys, using high pulse magnetic fields of up to about $30 \mathrm{MA} / \mathrm{m}$. The alloys investigated in their work were Fe-Ni, Fe-Ni-C, Fe-Ni-Mn, Fe-Pt, Fe-Ni-Co-Ti and Fe-Mn-C alloys, which include invar, ordered, ausaged, ferromagnetic or paramagnetic austenitic alloys. The primary aim of the present paper is to demonstrate that both athermal and isothermal martensitic transformations are able to be induced by ultra high magnetic fields even at room temperature in $\mathrm{Fe}-\mathrm{Ni}-\mathrm{Mn}$ and $\mathrm{Fe}-\mathrm{Ni}-\mathrm{Mn}-\mathrm{C}$ alloys which transform isothermally below room temperature under the normal conditions.

\section{EXPERIMENTAL METHOD}

The chemical composition of the alloys used in the present work is listed in Table 1 together with the nose-temperature, $\mathrm{T}_{\mathrm{m}}$, of the TTT diagram in isothermal martensitic transformation below room temperature. For the purpose of comparison, $\mathrm{Fe}-31 \mathrm{Ni}-0.3 \mathrm{C}$ and $\mathrm{Fe}-31 \mathrm{Ni}-10 \mathrm{Co}-3 \mathrm{Ti}$ (mass \%) alloys which exhibit athermal martensitic transformation at $130 \mathrm{~K}$ and $77 \mathrm{~K}$, respectively, were tested similarly in high pulse magnetic field. All of these alloys were made by vacuum induction furnace and, initially, ingots of $3 \mathrm{~kg}$ were produced. The application of ultra high pulse magnetic field on the specimens was conducted by an instrument shown schematically in Fig. 1. In this instrument, the pulse magnet is wound of $\mathrm{Cu}-\mathrm{Ag}$ alloy wire of which the cross section is $6 \mathrm{~mm} \times 4 \mathrm{~mm}$. The magnet immersed in liquid nitrogen is suspended from the top flange of liquid nitrogen vessel by a couple of SUS cylinders of concentric location that also works as current leads. The sample temperature in the insulated tube is maintained around room temperature by flowing nitrogen gas. The pulse magnetic field was increased stepwise with an increment of about 4 $\mathrm{MA} / \mathrm{m}$, reaching $47 \mathrm{MA} / \mathrm{m}$ at the final stage. The profile of a pulse magnetic field with time is shown in Fig. 2. It should be noted that the duration of the pulse is larger by three orders of magnitude than those previously used in the 
Table 1 Alloy composition, nose-temperature, $T_{m}$, marteniste volume fraction, $\mathrm{f}_{\mathrm{p}}$, induced by pulse magnetic field of $20 \mathrm{MA} / \mathrm{m}$, and martensite volume fraction, $\mathrm{f}_{\mathrm{s}}$, induced by holding under steady magnetic field of $17.5 \mathrm{MA} / \mathrm{m}$ for $2 \mathrm{~h}$..

\begin{tabular}{|c|ccc|c|c|c|}
\hline Alloy No. & \multicolumn{3}{|c|}{ mass \% (Fe,bal) } & $\mathrm{T}_{\mathrm{m}}(\mathrm{K})$ & $\mathrm{f}_{\mathrm{p}}(\%)$ & $\mathrm{f}_{\mathrm{f}}(\%)$ \\
\hline & $\mathrm{Ni}$ & $\mathrm{Mn}$ & $\mathrm{C}$ & & & \\
\hline 1 & 23 & 3.0 & 0 & -- & 45 & 85 \\
\hline 2 & 23 & 3.3 & 0 & 210 & 10 & 84 \\
\hline 3 & 23 & 3.6 & 0 & 170 & 1 & 78 \\
\hline 4 & 23 & 3.8 & 0 & 150 & 0 & 66 \\
\hline 5 & 23 & 4.0 & 0 & $<77$ & 0 & 3 \\
\hline 6 & 23 & 4.2 & 0 & $<77$ & 0 & 3 \\
\hline 7 & 22 & 3.6 & 0.1 & 110 & 1 & 59 \\
\hline
\end{tabular}

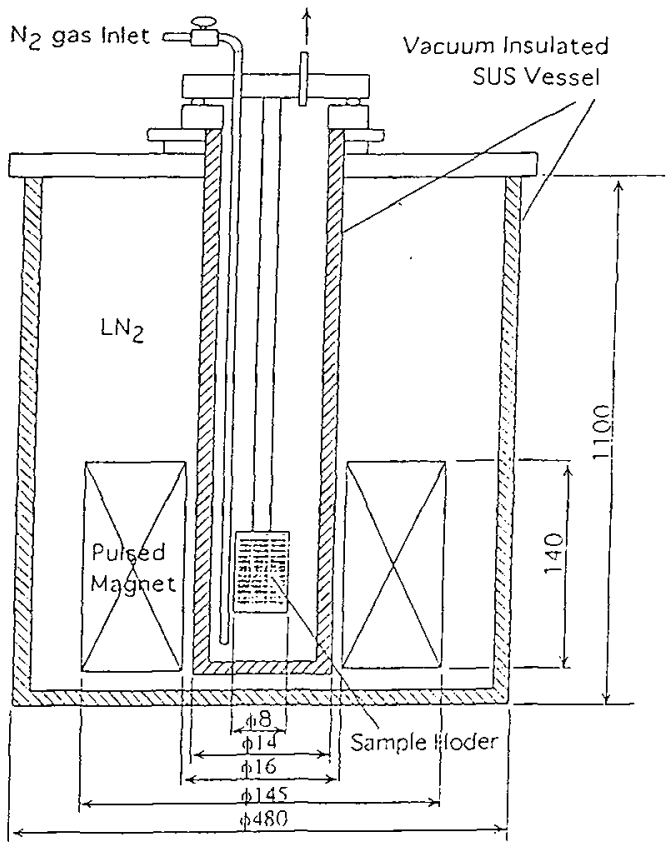

Figure 1: Schematic diagram of pulse magnet

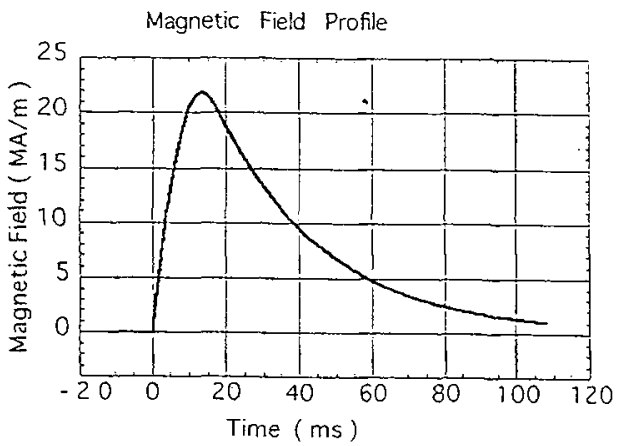

Figure 2: Profile of pulse magnetic field. 


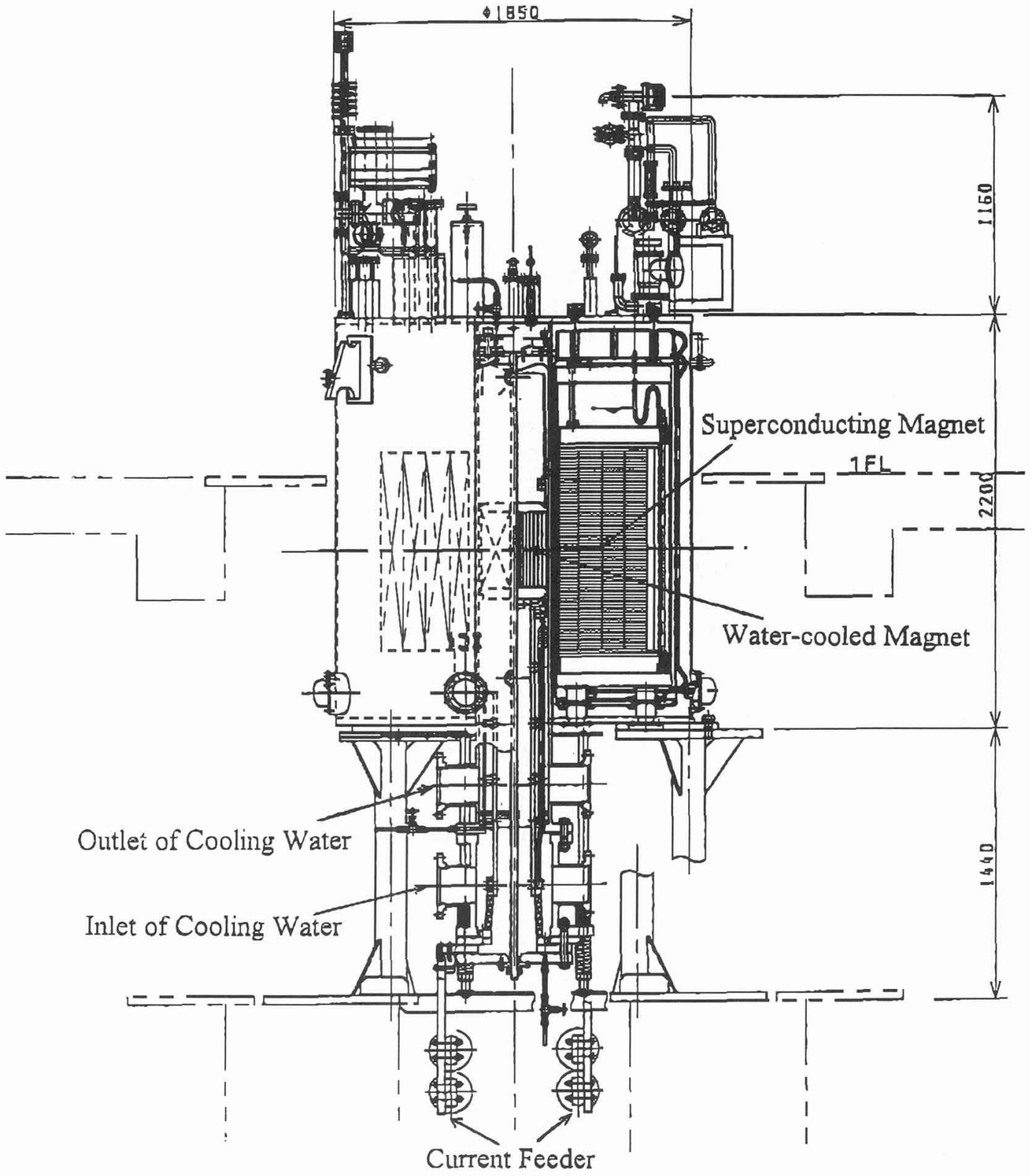

Figure 3: Structure of hybrid magnet with the steady magnetic field of $40 \mathrm{~T}(32 \mathrm{MA} / \mathrm{m})$ class strength. 
work by Kakeshita et al.[4,6,7]. Figure 3 shows the structure of a hybrid magnet with $40 \mathrm{~T}(32 \mathrm{MA} / \mathrm{m})$ class, which was constructed several years ago in our institute and has being operated since then $[2,3,4]$. The basic principle of this hybrid magnet is to combine the outputs of superconduction magnet and water-cooled magnet; the inner water-cooled magnet is able to generate an incremental field of $17.9 \mathrm{MA} / \mathrm{m}$ in a clear bore of $50 \mathrm{~mm}$ diameter under a background field of $11.3 \mathrm{MA} / \mathrm{m}$ generated by the outer superconduction magnet. The total field of 29.2 $\mathrm{MA} / \mathrm{m}$ is the present world record of steady magnetic field. The present experiment using this hybrid was done in such a condition that the steady magnetic field of $17.5 \mathrm{MA} / \mathrm{m}$ is applied on the specimens for $2 \mathrm{~h}$ at room temperature.

All the specimens were cold rolled by $90 \%$ at room temperature into about $0.7 \mathrm{~mm}$ thickness and, then, austenitized at $1370 \mathrm{~K}$ for $30 \mathrm{~min}$. This heat treatment of heavily rolled specimens produced a well-developed cube texture of the austenite for all the alloys and these textured plates $0.5 \mathrm{~mm}$ thick were employed in the experiment. For both cases of the pulse and steady magnetic field experiments, the magnetic field was always applied parallel to [100] of the cube texture of the austenite. The specimens with $0.5 \times 4 \times 10 \mathrm{~mm}$ in size were used for the both experiments and, in the case of the steady magnetic field experiment, disk specimens with $34 \mathrm{~mm}$ diameter cut into two pieces were also used in order to examine the texture of the magnetic field induced martensite. The amount of martensite was measured by a coil detector after each stepwise application of the pulse magnetic field in the pulse magnet experiment and, in the steady magnetic field experiment, it was measured after the $2 \mathrm{~h}$ run of the hybrid magnet. Except alloy 1, the specimens cooled from the above mentioned austenitizing temperature were completely austenitic at room temperature. The as-austenitized specimen of alloy 1 contained about $20 \%$ volume fraction of b.c.c. phase which is presumed to be martensite formed on cooling from the high temperature. The texture of the martensite was measured by X-ray pole figure method.

\section{RESULTS AND DISCUSSION}

Figure 4 shows the amount of martensite formed by pulse magnetic field as a function of the maximum strength, $H_{p}$, of magnetic field. It is seen in this figure that, for alloys $1,2,3$ and 7 , the amount of martensite is increased abruptly around $23 \mathrm{MA} / \mathrm{m}$ with increasing $\mathrm{H}_{\mathrm{p}}$ and reaches $70-80 \%$ martensite at $46.3 \mathrm{MA} / \mathrm{m}$ (the highest magnetic field in this experiment). For alloys 4 and 6 , the amount of the martensite is increased rather gradually with increasing $\mathrm{H}_{\mathrm{p}}$. A high level of the martensite amount of alloy $I$ in the range of $\mathrm{H}_{\mathrm{p}}$ below $20 \mathrm{MA} / \mathrm{m}$ is simply due to the fact the specimen contained thermally formed martensite before the test as mentioned in the preceding section. From the results shown in this figure, we can say that athermal martensitic transformation can be induced by high magnetic field at room temperature for the alloys which transform isothermally at low temperatures under the normal conditions. It is particularly interest to note that even alloy 6 of which $\mathrm{T}_{\mathrm{m}}$ is below $77 \mathrm{~K}$ is transformed into martensite as much as nearly $50 \%$ volume fraction. On the other hand, Fe-31Ni-0.3C and $\mathrm{Fe}-31 \mathrm{Ni}-10 \mathrm{Co}-3 \mathrm{Ti}$ alloys can not be transformed at room temperature even by applying the highest value of $\mathrm{H}_{\mathbf{p}}$. It should be also emphasized here that the kinetics of martensitic transformation in the present alloys is changed from isothermal to athermal by applying high magnetic field as already shown by Kakeshita et al. $[4,6,7]$ below room temperature.

In order to test if the isothermal martensitic transformation occurs at room temperature under a constant steady magnetic field of ultra high strength, a constant magnetic field of $17.5 \mathrm{MA} / \mathrm{m}$ was applied to the plate specimens of alloys 1-7 for $2 \mathrm{~h}$ at room temperature. The results are shown in Table 1 . In this table, $\mathrm{f}_{\mathrm{p}}$ represents the amount of martensite induced by pulse magnetic field of $20 \mathrm{MA} / \mathrm{m}$ and $\mathrm{f}_{\mathrm{s}}$ represents the amount of martensite formed under the steady magnetic field of $17.5 \mathrm{MA} / \mathrm{m}$ for $2 \mathrm{~h}$. It is evident that, for alloys 3-7, all the martensite represented by $\mathrm{f}_{\mathrm{s}}$ has been formed isothermally during the application of the constant magnetic field because $f_{p}$ in Table 1 is zero or nearly zero for these alloys, assuring that no athermal martensitic transformation occurs at the time of imposing the steady magnetic field on the specimens. In Fig. 5 , the value of $\mathrm{f}_{5}$ is plotted as a function of $\mathrm{Mn}$ content. It is seen in this figure that a small difference in Mn content for alloys 4 and 5 has produced a large difference of the resulting amount of martensite.

The martensite morphology observed by optical microscope is the same for all the alloys regardless of pulsemagnetic field induced or steady magnetic field induced martensite. Figure 6 shows a typical optical micrograph of surface relief of the martensite plates formed by steady magnetic field for alloy 4 . It was found that the morphology of martensite formed isothermally at low temperature under the normal conditions is also the same as that of Fig. 6 . 


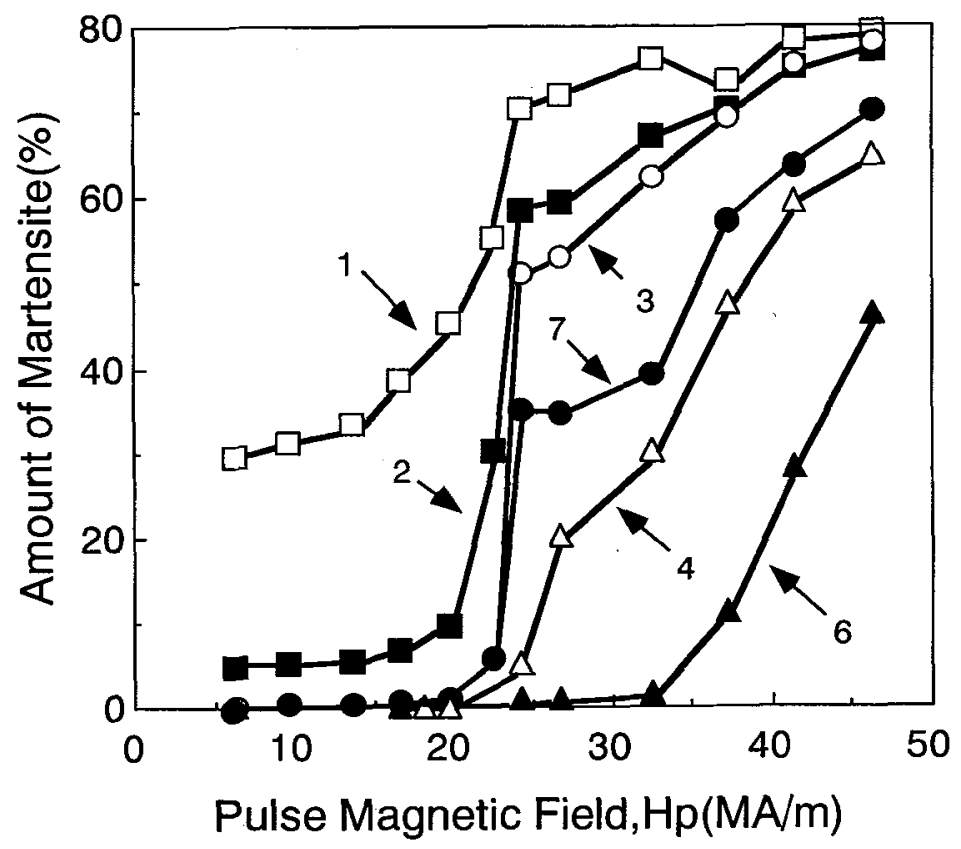

Figure 4: Amount of martensite as a function of the maximum strength of pulse magnetic field.

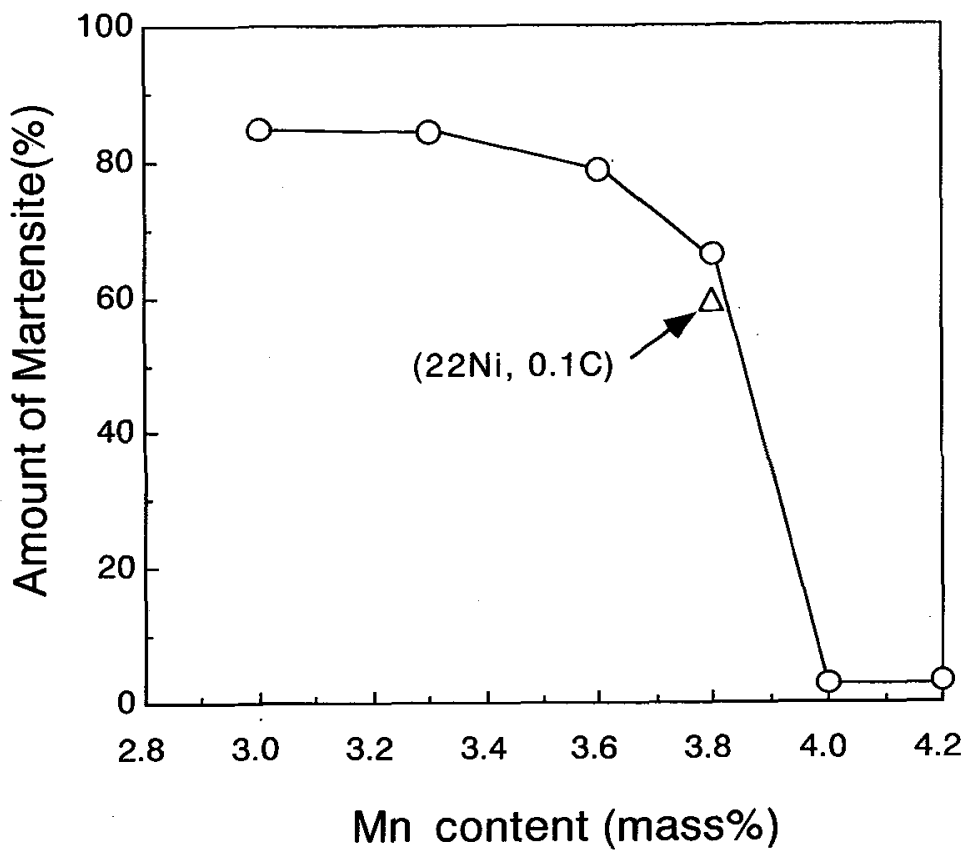

Figure 5: Amount of martensite formed isothermally at room temperature under a steady magnetic field of $17.5 \mathrm{MA} / \mathrm{m}$. The volume fraction of martensite is plotted as a function of Mn content in Fe-23Ni-xMn alloy. 


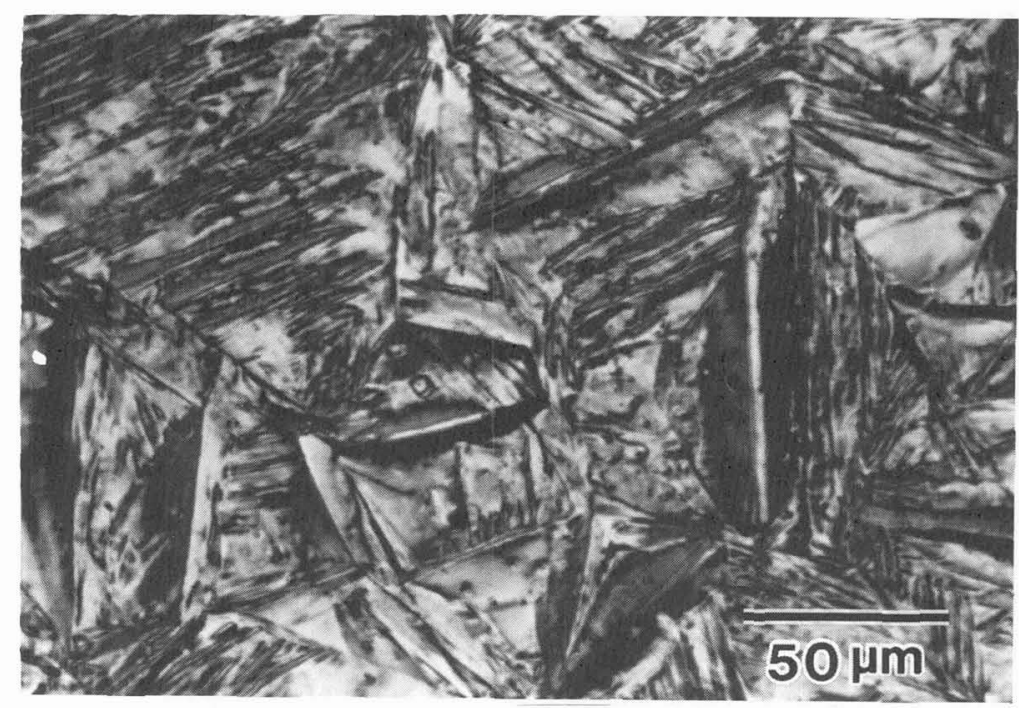

Figure 6: Optical micrograph of martensite (surface relief) formed isothermally at room temperature under the steady magnetic field of $17.5 \mathrm{MA} / \mathrm{m}$ (alloy 4 ).

The aforementioned striking effects of ultra high magnetic field in both pulse and steady magnetic field experiments seem to be too large to be explained simply by effects on the chemical driving energy due to various factors, such as magnetostatic, high field susceptibility and forced volume magnetostriction effects which were discussed in detail by Kakeshita et al [4-7].

The martensite texture formed isothermally at room temperature under the steady magnetic field of 17.5 $\mathrm{MA} / \mathrm{m}$ has two components; one is (110)[110] and the other is (110)[001]. The former texture has much stronger intensity than the latter one. Since the magnetic field was applied along the rolling direction, $\mathrm{R}$, one may consider that these textures have been produced due to the magnetic field. However, it tumed out that this is not true, for the exactly same martensite texture was produced by low temperature isothermal holding of those specimens. The texture of martensite formed during cooling from the high temperature range was also the same of those alloys. Therefore we can say that these textures have nothing to do with the applied magnetic field.

\section{References}

[1] T. Asano, Y. Sakai, G. Kido, K. Inoue and H. Maeda, Physica B 211 (1995) 46-49.

[2] K. Inoue, T. Kiyoshi, M. Kosuge, K. Itoh, T. Tadeuchi, H. Maeda, S. Hanai, M. Tezuka, T. Kojo, S. Murase, Y. Dozono and K. Matsutani., Physica B 216 (1996) 181-185.

[3] K. Inoue, T. Kiyoshi, M. Kosuge, T. Takeuchi, F. Matsumoto, H. Maeda, S. Hanai, M. Tezuka and K. Matsutani., IEEE Trans. on Magnetics, 32 (1996) 2450-2453.

[4] T. Kakeshita, K. Shimizu, S. Kijima, Z. Yu and M. Date., Trans. JIM., 26 (1985) 630-637.

[5] K. Shimizu and T. Kakeshita, ISIJ International, 29 (1989) 97-I 16.

[6] T. Kakeshita, K. Kuroiwa, K. Shimizu, T. Ikeda, A. Yamagishi and M. Date., Mater. Trans. JIM 34 (1993) $415-$ 422.

[7] T. Kakeshita, T. Yamamoto, K. Shimizu, K. Sugiyama and S. Endo., Mater. Trans., JM., 36 (1995) 1018-1022. 